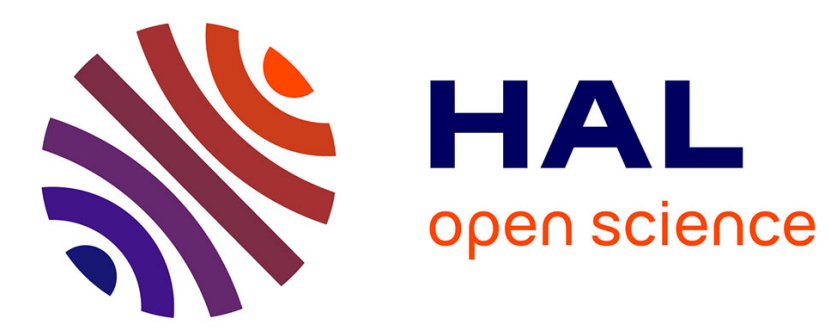

\title{
Thermal surface wave technique for thin film thermal diffusivity measurement
}

B. Zhang, R. Imhof, W. Hartree

\section{To cite this version:}

B. Zhang, R. Imhof, W. Hartree. Thermal surface wave technique for thin film thermal diffusivity measurement. Journal de Physique IV Proceedings, 1994, 04 (C7), pp.C7-643-C7-646. 10.1051/jp4:19947152 . jpa-00253211

\section{HAL Id: jpa-00253211 https://hal.science/jpa-00253211}

Submitted on 1 Jan 1994

HAL is a multi-disciplinary open access archive for the deposit and dissemination of scientific research documents, whether they are published or not. The documents may come from teaching and research institutions in France or abroad, or from public or private research centers.
L'archive ouverte pluridisciplinaire HAL, est destinée au dépôt et à la diffusion de documents scientifiques de niveau recherche, publiés ou non, émanant des établissements d'enseignement et de recherche français ou étrangers, des laboratoires publics ou privés. 


\title{
Thermal surface wave technique for thin film thermal diffusivity measurement
}

B. Zhang, R.E. Imhof and W. Hartree*

Department of Physics and Applied Physics, Strathclyde University, Glasgow G4 ONG, U.K.

* Quantum Metrology Division, National Physical Laboratory, Teddington TWII OLW, U.K.

\begin{abstract}
A new method of measuring thermal diffusivities of isolated thin films, using variable transverse displacement between focused, modulated optical excitation and radiometric detection, with measurements on metal and plastic foils, is presented.
\end{abstract}

\section{INTRODUCTION}

The main difficulty of measuring thermal diffusivity using opto-thermal radiometry is the separation of the property of interest from other material properties affecting the signal, principally optical absorbance [1]. The method reported here overcomes this by exploiting geometrical variables. A sinusoidally modulated light source is focused onto the sample surface, to produce a localized source of thermal waves, whose propagation can be measured at precisely located points from the source by means of a focused detector sensitive to the associated thermal infrared radiation. Thermal diffusivity is then calculated from measurements of magnitude and phase angle of the modulated infrared signal, in dependence on transverse displacement between excitation and emission spots and modulation frequency. In essence, this transverse opto-thermal radiometry technique, or T-OTR, measures the dispersion and attenuation of thermal waves close to the sample surface.

The transverse displacement measurement principle was first used by Kubiak [2] to scan for surface cracks in aircraft wings. Luukkala et al [3] suggested its use for thermal diffusivity measurement, but without giving details. Cielo et al [4] first reported a related technique that uses a concentric measurement geometry, with the excitation spread into a circle and the infrared emission detected at its centre. However, its main advantage of high sensitivity is counterbalanced in practice by the difficulty of varying the excitation radius and the stringent demands on the precision of the concentric symmetry. T-OTR is more robust and flexible in these respects, offering the added advantage of directional sensitivity for measurements on non-isotropic materials, at the expense of lower sensitivity.

\section{THEORY}

The oscillating component of the excess temperature field, $\theta(r)$, in the plane of a thermally thin sample of thickness $L$, excited by a heat source of negligible lateral extent, can be shown to be [5]

$$
\theta(r)=\frac{P_{0}}{4 \kappa L} e^{-j \frac{\pi}{2}} H_{0}^{(2)}\left(\frac{r}{\mu}(1-j)\right)
$$

where $\boldsymbol{H}_{0}^{(2)}$ is the zero order Hankel function of the second kind, $\boldsymbol{P}_{0}$ the optical power absorbed, $\kappa$ the 
thermal conductivity, $\mu=\sqrt{ }(D / \pi f)$ the thermal diffusion length, $f$ the modulation frequency and $D$ the thermal diffusivity. From this, the dependence of magnitude $M$ and phase angle $\Psi$ of the opto-thermal signal measured from a point source, displaced by a transverse distance $\boldsymbol{X}$ from the point of excitation, can conveniently be expanded as power series

$$
M(X)=\frac{\zeta P_{0}}{4 \kappa L} \sqrt{\frac{\sqrt{2} \mu}{\pi X}} e^{-\frac{X}{\mu}}\left(1-0.0625 \frac{\mu}{X}+0.001953 \frac{\mu^{2}}{X^{2}}+\ldots\right)
$$

and

$$
\Psi(X)=-\frac{X}{\mu}-0.3927+0.0625 \frac{\mu}{X}-0.03125 \frac{\mu^{2}}{X^{2}}+\ldots
$$

Where $\zeta$ is an instrumental sensitivity factor. These expressions are independent of the optical absorbances at the excitation and thermal emission wavelengths, because of the rapid equalisation of any temperature differences between the tops and bottoms of thermally thin samples. Furthermore, the extension of the theory to excitation and thermal emission areas of finite size shows that, for rotationally symmetric areas, Eqs.(2-3) can still be used as long as $\boldsymbol{X}>\boldsymbol{X}_{\boldsymbol{o}}$, where $\boldsymbol{X}_{\boldsymbol{o}}$ is the sum of their radii. In practice, deviations from these conditions, namely non-circular geometry and non-uniformity, do lead to systematic errors of measurement, as discussed in Section 4.

\section{APPARATUS}

A schematic diagram of the apparatus is shown in Figure 1. It was developed from our opto-thermal microscope [6], but abandons pulsed excitation in favour of sinusoidal modulation, because of its precise control of the optical waveform and intensity. Diode lasers with either $150 \mathrm{~mW}$ single-mode (SDL5422) or $500 \mathrm{~mW}$ multi-mode (SDL800) output are used for excitation. The $820 \mathrm{~nm}$ nominal wavelength radiation is passed through a spatial filter, deflection prism and focusing lens, to produce an irradiated spot on the sample surface of typically $<0.2 \mathrm{~mm}$ diameter. The prism and focusing lens are mounted together on a micro-positioning stage, to allow the excitation spot on the sample to be moved precisely and without

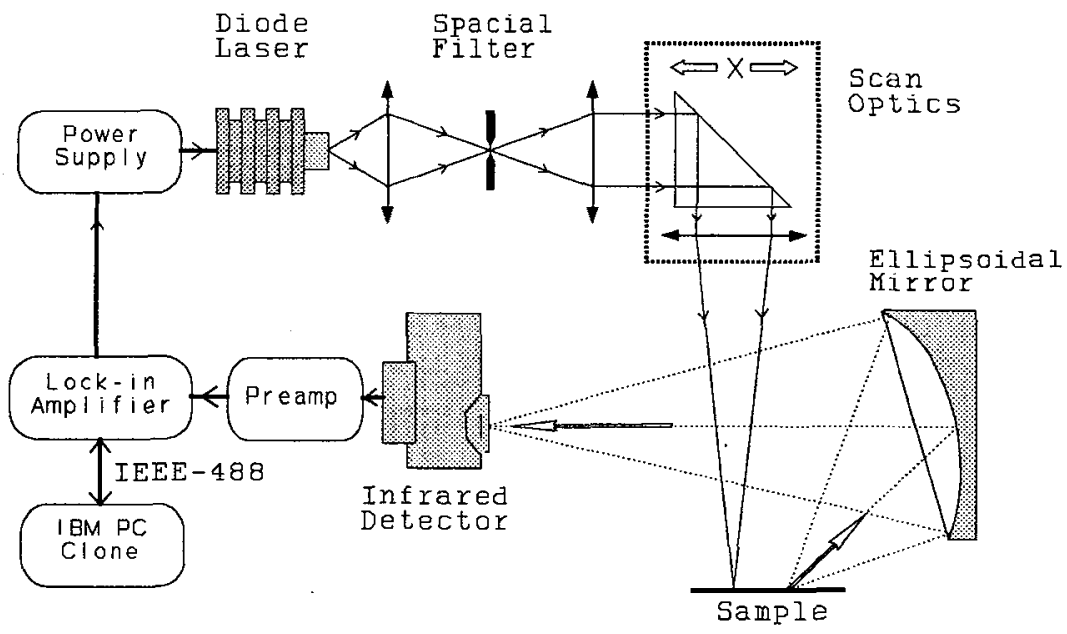

Figure 1 Schematic diagram of the T-OTR apparatus. 
distortion. An ellipsoidal mirror with approximately two times magnification is used to focus the thermal radiation from the sample onto a liquid nitrogen cooled Cadmium Mercury Telluride detector of $1 \mathrm{~mm}$ active area. The detector and sample holder are mounted on three-axis micro-positioners for precise alignment. A two-phase lock-in amplifier is used both to generate the modulation waveform applied to the diode laser and to measure the magnitude and phase angle of the radiometric signal. The lock-in amplifier is connected through an IEEE-488 interface to a PC for modulation control and data acquisition and analysis.

\section{RESULTS}

The method is illustrated in Figures 2 and 3 with measurements on a tantalum foil of $25 \mu \mathrm{m}$ thickness, supplied by Goodfellow Metals Ltd. Data at transverse displacements, where distortion due to overlapping of excitation and thermal emission areas was small, were analysed using global non-linear least squares programs. Best-fit thermal diffusivities of $D=2.22 \times 10^{-5} \mathrm{~m}^{2} \mathrm{~s}^{-1}$ and $D=2.74 \times 10^{-5} \mathrm{~m}^{2} \mathrm{~s}^{-1}$, with $\approx 3 \%$ statistical uncertainty, were calculated from magnitude and phase measurements respectively. These values are within the range of accepted values for multi-crystalline Tantalum.

It is clear from inspection of these data that the finite sizes of the excitation and thermal emission areas give rise to large deviations from the model of Eq.(1) at small values of $\boldsymbol{X}$. The prediction that, for uniform circular areas, Eqs.(2-3) can still be used as long as $\boldsymbol{X}>\boldsymbol{X}_{\boldsymbol{o}}$, appears well founded in the case of the magnitude data, which provide an estimate of the overlap distance of $\boldsymbol{X}_{\boldsymbol{o}}<1 \mathrm{~mm}$ in this case. However, the phase data, measured under identical conditions, show overlap distances that increase with modulation frequency. This is thought to be due partly to optical aberrations, leading to a spreading of excitation radiation and detection sensitivity beyond their geometrical images on the sample surface. In addition, any asymmetry in the distributions of radiation within the excitation area and sensitivity within the thermal emission area respectively will lead to phase angle measurement errors that increase with increasing frequency. Physically, this is because of increasing thermal wave attenuation with frequency, leading to a loss of signal contributions from points on the far sides of the excitation and thermal emission areas, and corresponding gains from stray radiation in the region between the two areas. However, least-squares analysis using magnitude data within $\approx 1 \mathrm{~mm}$, and phase data within $\approx 2 \mathrm{~mm}$ of the thermal emission point

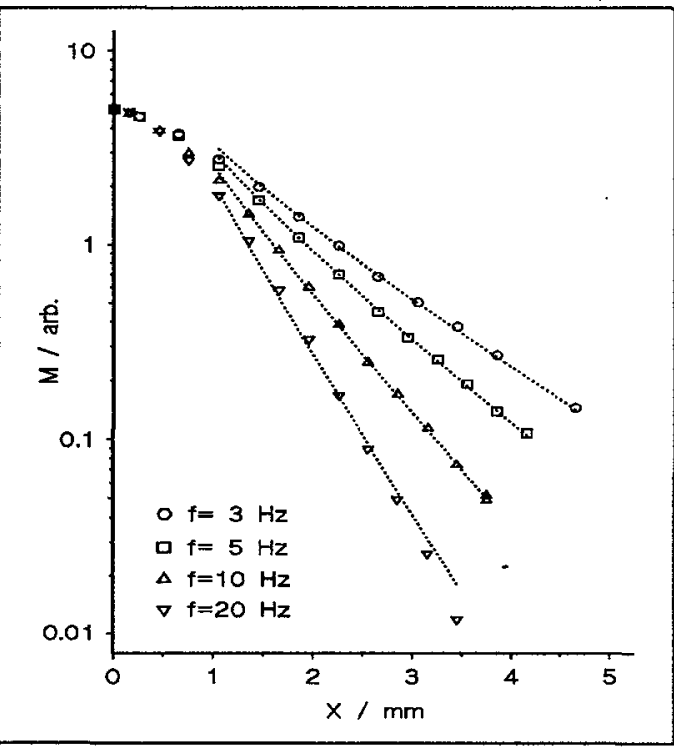

Figure 2 Measurement of thermal wave attenuation in $25 \mu \mathrm{m}$ thick tantalum foil.

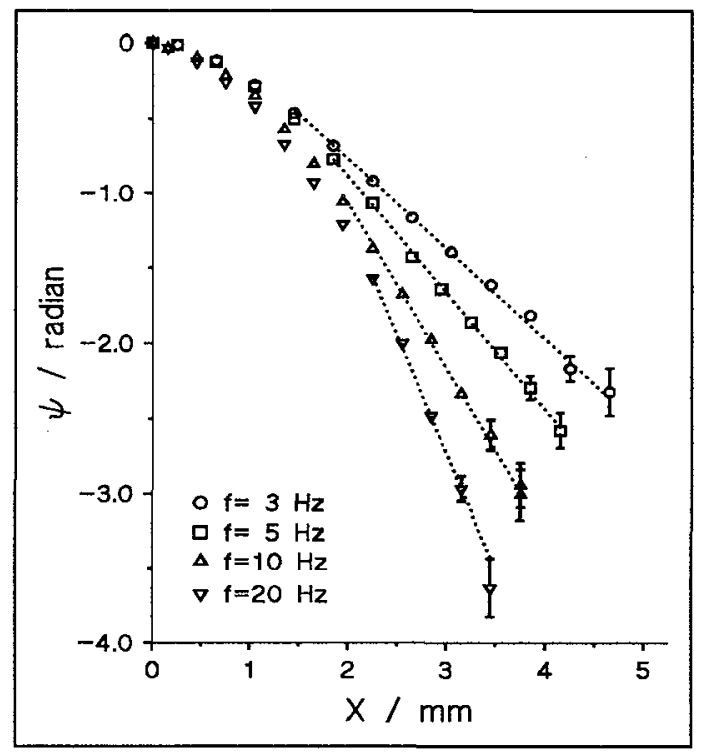

Figure 3 Measurement of the thermal wave propagation in $25 \mu \mathrm{m}$ thick tantalum foil. 
give acceptably accurate thermal diffusivity values.

of the two quantities measured, phase is thought to give more satisfactory results than magnitude. Phase measurements are independent of energy absorbed. This was illustrated with measurements on the outer surface of a Pepsi Cola can, where the transverse displacement included a change of colour from white to blue. This led to a large increase in the magnitude signal without affecting the phase angle. Magnitude measurements are also subject to more drift than phase measurements, because the steady heating component of the excitation causes the magnitude signal to increase with time, until the sample is in dynamic thermal equilibrium with its surroundings. This can take as much as ten minutes per excitation point, resulting in long measurement times. A measurement arrangement where the excitation spot remained stationary while scanning the thermal emission sensing area would be preferable from this point of view. Phase measurements are unaffected by such temperature rises and can therefore be measured more quickly. Disadvantages of phase measurement include the greater sensitivity to overlap errors and the greater intrinsic noise associated with it.

Measurements of low thermal diffusivities are

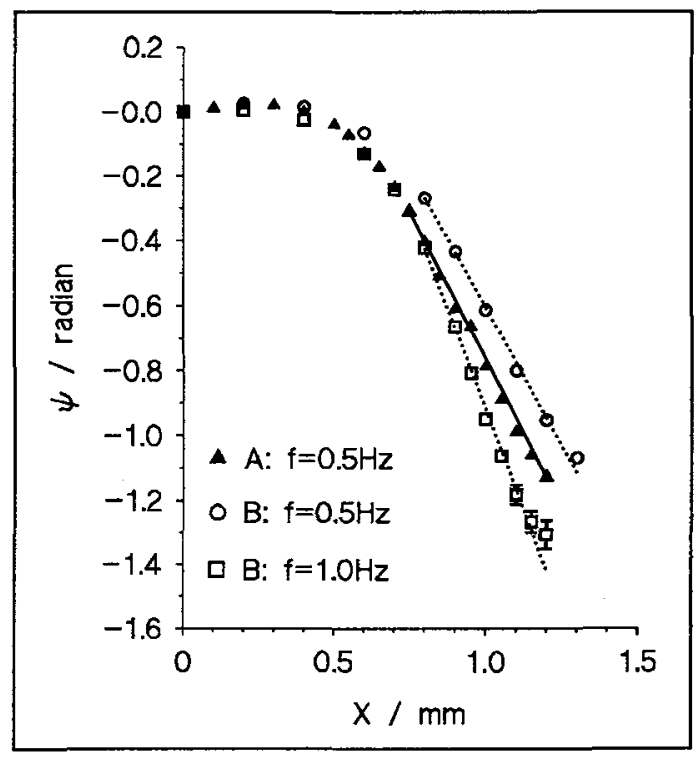

Figure 4 Thermal diffusivity measurement of anti-static packaging films for electronic components.

A: Semi-transparent, $76 \mu \mathrm{m}$ thickness.

B: Black, $73 \mu \mathrm{m}$ thickness. illustrated in Figure 4 with samples of anti-static packaging films for electronic components. Best-fit thermal diffusivities of $D_{A}=5.20 \times 10^{-7} \mathrm{~m}^{2} \mathrm{~s}^{-1}$ for a semi-transparent film of $76 \mu \mathrm{m}$ thickness and $D_{B}=4.62 \times 10^{-7} \mathrm{~m}^{2} \mathrm{~s}^{-1}$ for a black film of $73 \mu \mathrm{m}$ thickness, with $\approx 4 \%$ statistical uncertainty, were calculated from these data. They represent the lower limit of thermal diffusivity that can be measured with the present apparatus.

\section{CONCLUSIONS}

The technique is capable of measuring absolute thermal diffusivity of a wide range of materials. The work shows that phase measurements are quicker to perform and have less drift and systematic errors associated with them than magnitude measurements. Work is now in progress to improve the focussing of the apparatus and to extend the method of analysis to take overlap distortion into account.

\section{Acknowledgment}

We thank the SERC and NPL for research support and John Reevie for his invaluable technical assistance.

\section{References}

[1] Imhof R.E. Zhang B. and Birch D.J.S. (Progress in Photothermal and Photoacoustic Science and Technology II, Editor: Mandelis A. PTR Prentice Hall, Englewood Cliffs 1994) 185-236.

[2] Kubiak E.J. Appl.Opt. 7(1968) 1743-1747.

[3] Luukkala M. Lehto A. Jaarinen J. and Jokinen M. IEEE Ultrason. Symp.(1982) 591-594.

[4] Cielo P. Utracki L.A. and Lamontagne M. CanJ.Phys. 64(1986) 1172-1177.

[5] Zhang B. and Imhof R.E., to appear in Meas.Sci.Techn.

[6] Imhof R.E. Moksin M.M. Webb J.F. Willson P.H. Birch D.J.S. and Strivens T.A. Brit.J.NDT 33(1991) 172-176. 